This report was prepared as an account of work sponsored by an agency of the United States LBL -26012 Government. Neither the United States Government nor any agency thereof, nor any of their employees, makes any warranty, express or implied, or assumes any legal liability or responsibility for the accuracy, completeness, or usefulness of any information, apparatus, product, or process disclosed, or represents that its use would not infringe privately owned rights. Reference herein to any specific commercial product, process, or service by trade name, trademark. manufacturer, or otheruise does not necessarily constitute or imply its endorsement, recommendation, or favoring by the United States Government or any agency thereor. The views and opinions of authors expressed herein do not necessarily state or reflect those of the United States Government or any agency thereof.

\title{
Magnet Power Supplies for the Advanced Light Source
}

\author{
L. Terry Jackson and Ivan C. Lutz \\ Accelerator and Fusion Research Division \\ Lawrence Berkeley Laboratory \\ 1 Cyclotron Road \\ Berkeley, California 94720
}

Paper presented at the 1989 Particle Accelerator Conference in Chicago, Illinois, March 20 to 23, 1989

This work was supported by the Director, Office of Energy Research, Office of Basic Energy Sciences, Materials Sciences Division of the U. S. Department of Energy under Contract No. DE-AC03-

$76 S F 00098$ 


\author{
L. T. Jackson and I. C. Lutz \\ Lawrence Berkeley Laboratory \\ University of California \\ Berkeley, California 94720
}

\section{Abstract}

The Lawrence Berkeley Laboratory (LBL) is building an Advanced Lighi Source (ALS) to produce synchrotron radiarion. An electron linear accelerator, and a booster synchrotron are used to accelerate the electron beam to $1.5 \mathrm{GeV}$ to fill the storage ring. This paper describes the power supplies used for the magnets in the booster and the storage ring and the interface requirements for computer control and monitoring of the power supplies and magnet currents.

\begin{tabular}{llll} 
Magnet & Amps & Volts & Tracking \\
\cline { 2 - 4 } Bending & 800 & 1175 & na \\
Quad QF & 460 & 245 & $0.1 \%$ \\
Quad QD & 460 & 245 & $0.1 \%$ \\
Sext SF & 6 & 130 & $0.5 \%$ \\
Sext SD & 6 & 92 & $0.5 \%$ \\
Correction & & & \\
Dipoles & $+/-6$ & $36 \mathrm{v}$ ea & $0.5 \%$
\end{tabular}

Table 1. Booster Magnets Power Supplies

\section{Booster Bendine Magnets Power Supply}

The 24 bending magnets in the booster are electrically connected in series and powered by an unregulated. SCR controlled, power supply capable of operating in the inversion mode as well as the rectification mode.

The boosrer operates at 1 cycle per second. At the start of each cycle the SCRs are phased for full output voltage and the current builds up in the magnets on the magnets $L / R$ time constant from 0 to 738 amps in about 0.45 seconds (aceclerating the electron beam from $50 \mathrm{MeV}$ to $1.5 \mathrm{GeV}$ ) at which time the SCRs are phased for inversion transferning the energy stored in the magnets back to the power line and the magnets current decays to zero in time for the next cycle. (see Figure 1)

The bending magnets current does not need to be regulated (eg a linear ramp) if the magnetic fields of the other magnets in the booster track the magnetic field of the bending magnets to the required accuracy during the beam acceleration portion of the cycle.

\section{Booster Tracking Accuracy}

The tracking accuracy requirements during the beam acceleration portion of the cycle are $0.1 \%$ for the quadrupole magnets and $0.5 \%$ for the sextupole and correction dipole magnets. There are no tracking requirements during the magnets de-energizarion portion of the cycle.

The specified tracking requirements applies at the beam injection energy of $50 \mathrm{MeV}$ as well as all during the beam accelerarion to $1.5 \mathrm{GeV}$ portion of the machine operation cycle. Referred to peak magnet current, the tracking accuracy is about $33 \mathrm{E}-5$ for the quadrupoles and 1.67E-A for the sextupoles and the correction dipoles.

A precasion DC current transductor (DCCT) monitoring the bending magnets current is used to generate a voltage proporional to current. This voltage is used as a reference signal for the power supplies of the other magnets in the booster. Since the magnet current is monitored instead of the magnetic field, if the magnetic field is not linear with the magnet current to the degree required a sofnware program will be written to generate a correction voltage to be mixed with the DCCT output voltage to makc the reference voltage linear with the magnetic field (see Figure 2). This provision is made for each of the magnets in the booster.

\section{Booster Current Monitoring}

The magnet current of each of the magnet families in the booster is monitored with a DCCT or a resistor generating a voltage proportional to current. Each of the voltages are connected to a separate sample and hold circuit so that all of the currents can be read at the same time within a window of less than 100 microseconds. The output of the sample and hold circuits are then read by ADCs and compared in the computer to see if they are tracking to within the required accuracy.

\section{Current Range Control}

As the bending magnets current increases from zero to 738 amps each cycle (increasing the beam energy to $1.5 \mathrm{GeV}$ ) the current in the other magnets may not be required to increase to the maximum listed in the above table. For example, the quadrupole current at $1.5 \mathrm{GeV}$ needs to be adjusrable from 200 to 160 amps.

This range change is done by feeding the reference voltage from the bending magnets DCCT thru an analog multiplier with a transfer function of $(V x V y) / 10$. The reference voltage is $V x$ and $\mathrm{Vy}$ is obtained from a digital to analog converter (DAC) in the Intelligent Local Controller (ILC) [1] allowing the computer to control the peak magnet current at $1.5 \mathrm{GeV}$. This range control feature applies to all of the magnets (except the bending magnets) in the booster.

\section{Analog to Digizal Converter (ADC) Requirements}

The tradking accuracy of the quadrupole magnets is $0.1 \%$ at injection as well as all during the acceleration portion of the cycle. The minimum range current at injection is about 6.5 amps. The DCCT monitoring the quadrupole curtent is rated 10 volts at 480 amps so at injection the DCCT voltage is only 0.135 volts and $0.1 \%$ of 0.135 volts is 135 microvolts. 135 mictovolts is 1 part in 74,000 of 10 volts. A true 17 bit 0 to 10 volt $A D C$ with a resolution of 1 part in 131.000 is required to be able to read the magnet current with sufficient resolution to compare it to the bending magnets current to see if the quadrupoles are tracking to within $0.1 \%$.

The ADC requirements for the sextupole and correction dipole magnets is essentially the same even though the tracking accuracy is relaxed to $0.5 \%$ because these magnets may be required to have a range greater than that of the quadrupoles.

\section{Booster Quadrupole Magnets Pawer Supplies}

There are 16 focusing quadrupole magnets and 16 defocusing quadruole magnets in the booster array. The focusing quadrupoles (QF) are electrically connected in senes and powered by one power supply and the defocusing quadrupoles (QD; are electrically connected in series and powered by another power supply.

The power supplies for these two magnet families are custom built for this application and are current regulated by means of

This work was supported by the Director, Oflice of Energy Rescarch, Office of Basıc Energy Scıences, Matenal Sciences Divisıon, of the U.S. Deparment of Energy under Contract No. DE-AC03-76SF01k98. 


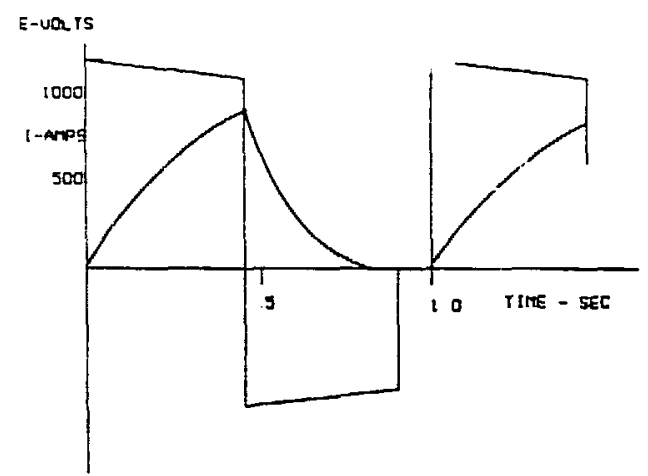

Figure 1. Booster Bending Magnets Voltage and Current Waveforms

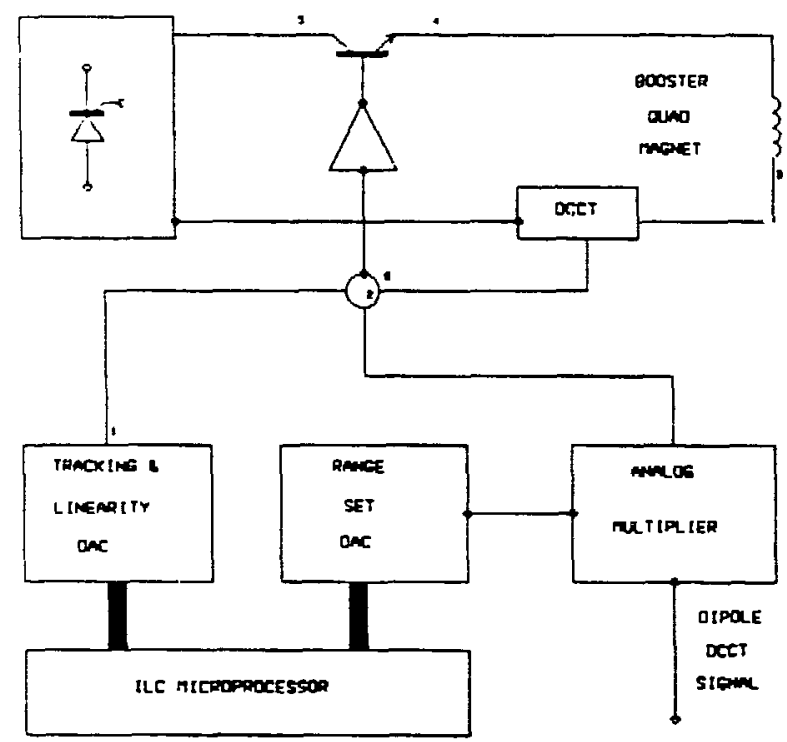

Figure 2. Typical Booster Power Supply Dynamic Reference System

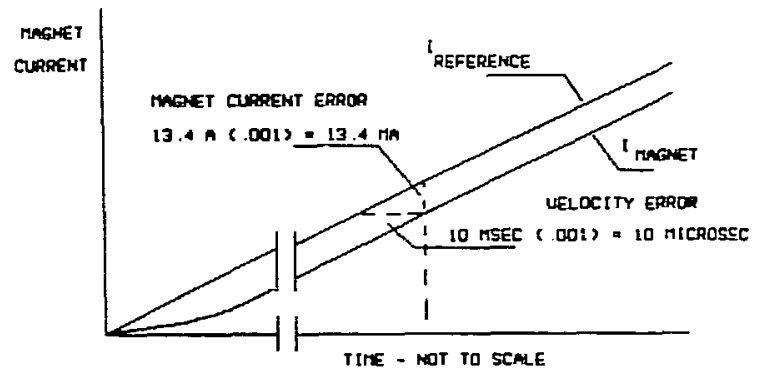

MOTE. OROIMATES nOT TO STMLE

STAPTINC TRMSIEATS RUST SETTLE TO UITHIN $0 . \%$ BT T-10 RSEC

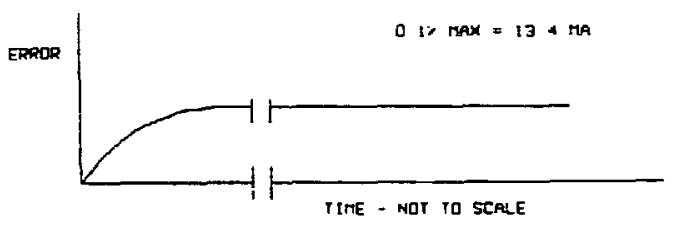

The velocity error is equivalent to the time constant of the step response of the closed-ioop system, Therefore the closed-loop bandwidth must be, $r_{c}=(2 \mathrm{piT})^{-1}=\left(2 \mathrm{pil}^{-5}\right)^{-2}=16 \mathrm{kHz}$.

Figure 3. Booster Quadrupole Tracking Requirements 
series transistors driving the magnets in an emitter follower configuration to obtain the closed-loop bandwidth of about 16 $\mathrm{kHz}$ required to meet the tracking requirements (see Figure 3 ). A precision DCCT with a wide bandwidth is used to derive a voltage proportional to magnet current for use as the feedback signal for the current regulator and for the computer to monitor the current. The two supplies are identical.

\section{Booster Sextupole Maonets Power Supplies}

There are 20 sextupole magnets in the booster magnet array. These magnets are connected into two families of 12 and 8 magnets each and powered by two power supplies or if suitable power supplies cannot be purchased, the magnets on be connected in groups of less than 12 and 8 and the computer can monitor the tracking accuracy of the groups. Commercially available power supplies are presently being evaluated for this application, however, the requirement for a tracking accuracy of $0.5 \%$ at beam injection (about $50 \mathrm{~mA}$ or less) is beyond the capabilities of most powrer supplies in this range.

\section{Booster Correction Dipole Magnets Power Supplies}

There are 16 horizontal and 16 vertical correction dipole magnets in the booster magnet array. Each of the magners is to have its own bi-polar power supply which can be computer controlled. The maximum current at $1.5 \mathrm{GeV}$ is $+/ .6$ amps. The maximum voltage required for for tracking the bending magnets current waveshape is about $+/-9$ volts. It is desired to have the capabilities of changing the $\mathrm{dI} / \mathrm{dt}$ of the correction magnets during the beam acceleration portion of the cycle to approximately four times normal so a power supply voltage of about 36 volts is being considered.

Commercialiy available bi-polar power supplies are presently being evaluated for this application. but as mentioned above for the sextupole magnets, the requirement of a tracking accuracy of $0.5 \%$ at the beam injection energy of $50 \mathrm{MeV}$ is beyond the capabilities of most catalog item power supplies.

\begin{tabular}{|c|c|c|c|}
\hline Magnet & Amps & Volts & Stability \\
\hline Bending & 970 & 536 & $+/-5.0 \mathrm{E}-5$ \\
\hline $\begin{array}{l}\text { Quadrupole } \\
\text { Family QFA } \\
\text { QF } \\
\text { QD }\end{array}$ & $\begin{array}{l}507 \\
113 \\
113\end{array}$ & $\begin{array}{r}350 \\
45 \\
33\end{array}$ & $\begin{array}{l}+/-1.0 \mathrm{E}-4 \\
+/-1.0 \mathrm{E}-4 \\
+/-1.0 \mathrm{E}-4\end{array}$ \\
\hline $\begin{array}{l}\text { Sextupole } \\
\text { Family SF } \\
\text { Family SD } \\
\text { Jikew Quad } \\
\text { Vert. Corr. } \\
\text { "Horiz Cort. }\end{array}$ & $\begin{array}{r}395 \\
395 \\
15 \\
+/-19 \\
+/-21\end{array}$ & $\begin{array}{r}200 \\
200 \\
30 \\
40 \\
45\end{array}$ & $\begin{array}{l}+/-1.0 \mathrm{E}-3 \\
+/-1.0 \mathrm{E}-3 \\
+/-1.0 \mathrm{E}-3 \\
+/-5.0 \mathrm{E}-4 \\
+/-5.0 \mathrm{E}-4\end{array}$ \\
\hline $\begin{array}{l}\text { Correction } \\
\text { Horizontal } \\
\text { Vertical }\end{array}$ & $\begin{array}{r}+/-33 \\
+/-116\end{array}$ & $\begin{array}{l}25 \\
15\end{array}$ & $\begin{array}{l}+/-5.0 E-4 \\
+/-5.0 E-4\end{array}$ \\
\hline
\end{tabular}

Table 2. Storage Ring Magnets Power Supplies

\section{Storage Ring Marnets Current Control ard Monitoring}

The control and monitoring of the current in the storage ring magnets is done by dedicated DACs and ADCs for each magnet power supply. There is no tracking requirements. When the beam in the storage ring is ramped from 1.5 to $1.9 \mathrm{GeV}$ the ramp is slow enough that the computer can adjust the magnet currents on an individual basis. There is no need for sample and hold circuits to read the magnet current.

The dedicated ILCs mounted in the power supply racks each contaun four ADCs and four DACs and can monitor and control four magnet power supplies.
Precision DCCTs are planned for monitoring the bending magnets current, the quad family QFA current, and the sextupole families SF and SD currents. The merhod of monitoring the magnet currents in the auxiliary windings on the sextupole and the correction dipole magnets has not yet been decided.

\section{Storage Ring Bending Magnets Power Supply}

The 36 bending magnets in the storage ring array are electrically connected in series and powered by one power supply. The toral circuit inductance is about 0.6 henrys and the resistance is about 0.55 ohms. The design operating range for the storage ring is from 1.0 to $1.9 \mathrm{GeV}$ which results in a current range from 477 to 924 amps. The current stability of $+/-5.0 \mathrm{E}-5$ applies over the entire range. This power supply will be built to LBL specifications and is anticipated to use series transistors for current regulation and will use a precision DCCT to monitor the magnet current.

\section{Storage Ring Quadrupole Magnets Power Supplies}

There are 24 horizontally focusing quadrupole magnets electricaily connected in series in the storage ring magnet array known as quadrupole family QFA. These magnets are powered by one power supply. The inductance of the total circuit is about $133 \mathrm{mH}$.

The magnet current stability requirements are $+/-1.0 \mathrm{E}-4$ so a series transistor curtent regulared power supply will be custorn built per LBL specifications. A precision DCCT will be used to monitor the magnet current.

The storage ring also has 24 horizontally focusing quadrupole magnets (known as QF) and 24 vertically focusing quadrupole magnets (known as QD) each with individual power supplies. The required magnet current stability is $1.0 \mathrm{E}-4$ and the configuration of the power supplies and the method of monitoring the magnet current has not yet been decided.

\section{Storage Ring Sextupole Magnets Power Supplies}

The 48 sextupole magnets in the storage ring each have four windings: sextupole, horizontal corrector, vertical corrector, and strew quadrupole windings.

Twenty-four of the sextupole windings are connected in series (known as family SF) and are powered by one power supply. The other 24 are connected in series (known as family SD) and are powered by another power supply. These power supplies are planned to be current regulared by means of SCRs. The current monitor has not been chosen at this time.

Each of the vertical and horizontal corrector windings has a separate power supply which needs to be bi-polar with current stabilities in the order of $+/-5.0 \mathrm{E}-4$.

Sixteen of the skew quadrupole windings are connected in four families of four magnets each. Each family of magnets will have its own power supply.

\section{Storage Ring Correction Dinole Magnets Power Supplies}

There are 96 correction dipole magnets in the storage ring. The power supplies for these magnets and the ones for the correction windings on the sextupole magnets are required to be bipolar with smooth transistion thru zero. Commercially available power supplies are being evaluated at this time. The addition of exiernal current stabilizing loops around commercial power supplies as well as open loop periodic zerc drift cancellation circuits are being considered.

\section{Reference}

[1] S. Magyary, et al, "Advanced Light Source Control Svstem", this conference 